\title{
The capacity to generate alternative ideas is more important than inhibition for logical reasoning in preschool-age children
}

\author{
Pier-Luc de Chantal $^{1} \cdot$ Henry Markovits ${ }^{1}$
}

Published online: 10 October 2016

(C) Psychonomic Society, Inc. 2016

\begin{abstract}
There is little consensus about the nature of logical reasoning and, equally important, about how it develops. To address this, we looked at the early origins of deductive reasoning in preschool children. We examined the contribution of two factors to the reasoning ability of very young children: inhibitory capacity and the capacity to generate alternative ideas. In a first study, a total of 32 preschool children were all given generation, inhibition, and logical reasoning measures. Logical reasoning was measured using knowledgebased premises such as "All dogs have legs," and two different inferences: modus ponens and affirmation of the consequent. Results revealed that correctly reasoning with both inferences is not related to the measure of inhibition, but is rather related to the capacity to generate alternative ideas. In a second study, 32 preschool children were given either the generation or the inhibition task before the logical reasoning measure. Results showed that receiving the generation task beforehand significantly improved logical reasoning compared to the inhibition task given beforehand. Overall, these results provide evidence for the greater importance of idea generation in the early development of logical reasoning.
\end{abstract}

Keywords Deductive reasoning · Development $\cdot$ Idea generation $\cdot$ Inhibition $\cdot$ Preschool

Deductive reasoning plays a role in many of our cognitive activities and is necessary to understand mathematics and science. Logical deduction involves the ability to draw a valid

Pier-Luc de Chantal

pldechantal@gmail.com

1 Université du Québec à Montréal, Montréal, QC, Canada conclusion that can be derived necessarily from the information at hand and to distinguish valid from merely possible conclusions. There is a large body of research that has looked at logical deduction, both in children and adults. Despite its importance, there is still little consensus about the nature of logical reasoning, and equally important, about how it develops and what are the mechanisms behind this development. In the following studies, we examine the early beginnings of the ability to make logical deductions in 3- to 5-year-olds.

Specifically, we look at an elementary form of deductive reasoning analogue to conditional reasoning. Conditional reasoning is perhaps one of the most intensely studied forms of deductive reasoning (Evans, Newstead, \& Byrne, 1993). It involves making inferences on the basis of a major premise of the form "If $\mathrm{P}$ then Q" and a minor premise that either asserts or denies the antecedent $(\mathrm{P})$ or the consequent $(\mathrm{Q})$ term. This gives rise to four distinct inferences. One of these is the modus ponens (MP), which uses the premises "If $\mathrm{P}$ then Q. P is true." and leads to the logically valid conclusion "Q is true." The modus tollens (MT) uses the premises "If P then Q. $\mathrm{Q}$ is false." and leads to the logically valid conclusion " $\mathrm{P}$ is false." The affirmation of the consequent (AC) uses the premises "If P then Q. Q is true." and leads to the logically invalid conclusion "P is true." Finally, the denial of the antecedent (DA) uses the premises "If P then Q. P is false." and leads to the invalid conclusion " $\mathrm{Q}$ is false." Neither the AC nor the DA inferences lead to logically valid conclusions because they are uncertain given the premises.

There are relatively few studies that have examined conditional reasoning in very young children. Among these studies, some have shown that even preschool children are often capable of making logical inferences with the MP inference or the syllogistic equivalent "All P are Q. R is P. Therefore R is Q." (e.g., Dias \& Harris, 1988). This is consistently the case for premises that are believable or for nonsense premises 
(Hawkins, Pea, Glick, \& Scribner, 1984), although young children have difficulty in making the MP inferences with premises that are unbelievable (Dias \& Harris, 1988, 1990; Hawkins et al., 1984). However, when these are embedded into some kind of fantasy or imaginary context, this difficulty disappears (Dias \& Harris, 1988, 1990; Dias, Roazzi, O’Brien, \& Harris, 2005; Markovits, 1995; Richards \& Sanderson, 1999). Studies have also consistently shown that young children tend to erroneously accept the AC (and DA) inference as well (see O'Brien \& Overton, 1982). In fact, developmental changes in conditional reasoning are primarily characterized by a decrease in the rate of acceptance of the uncertain conclusions. However, this is also moderated by strong content effects (for an overview, see Markovits, 2014a). Even young elementary school-age children can, with appropriate content, correctly reject the AC inference (Markovits, 2000; Markovits \& Thompson, 2008). In a similar vein, Rumain, Connell, and Braine (1983) found that when the effects of implicit pragmatic inferences are undone by presenting explicit information, performance on the $\mathrm{AC}$ (and DA) inference improves significantly among elementary school children.

These basic results have been interpreted in two very different ways. On the one hand, some theories of reasoning consider that logical reasoning is essentially algorithmic and rule based (Braine, 1990; Braine \& O’Brien, 1991; Rips, 1983, 1994). These posit that even young children have access to a basic set of rule schemas, which in turn are used to draw deductive inferences. Thus, it has been claimed that young children should have access to the syntactic rules of inference underlying certain simple inferences (Dias \& Harris, 1988, 1990; Hawkins et al., 1984; Rumain et al., 1983). Within this theoretical framework, difficulties in making these inferences are explicable by some form of inhibitory failure. Failure to make logically correct inferences has been ascribed to an inability to inhibit implicit pragmatic influences that can alter the interpretation of conditional rules. A similar analysis would start from the well-known fact that the MP inference is both the easiest to make correctly among adults and is the earliest form of inference consistently found in very young children (Dias \& Harris, 1988, 1990; Hawkins et al., 1984). Given that the major premise in a conditional syllogism (i.e., "If P then Q") or equivalent clearly suggests the truth of the MP inference (i.e., "P is true, therefore $Q$ is true"), the difficulty in correctly responding to the AC inference could be a result of a difficulty in inhibiting the suggested MP inference schema. In either case, such an approach would suggest that young children have a basic logical capacity, but that failure to inhibit other forms of information or resist salient inferences would make deploying this capacity difficult.

There is clear evidence that limited inhibitory capacity and poor monitoring of conflicting information are important factors in the cognitive difficulties of preschool children. When unaided, preschool children have trouble inhibiting the most salient response or information at hand (Diamond, Kirkham, \& Amso, 2002). Studies have indeed shown a striking increase in children's inhibitory capacity between the age of 3 and 6 years (Carlson \& Moses, 2001; Diamond \& Taylor, 1996; Gerstadt, Hong, \& Diamond, 1994; Livesey \& Morgan, 1991). This is in turn consistent with the observation that unaided logical reasoning with both MP and AC inferences does not clearly appear until around 6 or 7 years of age (Markovits \& Thompson, 2008).

However, there is another approach to young children's logical abilities, which suggests a second important factor. Specifically, there is increasing evidence that a key component of logical reasoning is the ability to generate information not directly contained in the reasoning problem. Piaget's (1987a, 1987b) later formulation of cognitive development already emphasized the interaction between logical necessity and the ability to generate "possibilities" (see also Gauffroy \& Barrouillet, 2011). Similarly, a key component of mental model theories of reasoning is the ability to generate alternative models (Johnson-Laird, 2006; Johnson-Laird \& Byrne, 1991, 2002; Markovits \& Barrouillet, 2002).

We can understand this best within a mental model framework. Young children tend to accept all four inferences when content is not appropriate (Markovits, 2000), which corresponds to a biconditional set of models:

$$
\begin{array}{ll}
\mathrm{P} & \mathrm{Q} \\
\text { not-P } & \text { not-Q }
\end{array}
$$

Each row refers to a possible situation that is consistent with the premises. The key difference between biconditional and conditional models is the incorporation of a third model, which corresponds to the last row:

$$
\begin{array}{ll}
\mathrm{P} & \mathrm{Q} \\
\text { not-P } & \text { not- } \mathrm{Q} \\
\text { not-P } & \mathrm{Q}
\end{array}
$$

Such a model corresponds to an alternative antecedent (i.e., cases of A implies Q, where A is an example of not-P). For example, given the premise "If a rock is thrown at a window, the window will break," throwing a chair at a window is an example of such an alternative. Markovits and Barrouillet (2002) suggested that the incorporation of alternative models could be understood as a form of information generation. A key component of this process is the idea that information about alternative antecedents is constrained by the associative structure of information related to the premises (Quinn \& Markovits, 1998). A significant component of individual differences in the ability to respond correctly to the uncertain inferences (AC and DA) is the ability to generate alternative antecedents that are only weakly associated to the consequent term (Markovits \& Quinn, 2002). It should also be noted that 
this approach is similar to Byrne's (2005) analysis of the rational imagination, although there are differing details.

Critically, information about alternative antecedents is not explicitly contained in the premises, but must be generated during the reasoning process. Thus, such an approach suggests that a key component of logical reasoning with $\mathrm{AC}$ (and DA) inferences rest upon the ability to generate additional information that is not directly presented in the premises. In other words, a key unresolved question is whether the beginnings of logical reasoning is more strongly related to the ability to generate alternative ideas or to the ability to inhibit information. The main aim of these studies was thus to examine the comparative relation between idea generation and inhibition in the early development of logical reasoning. Finally, it is important to note that in the following studies, we define logical reasoning as being the ability to both accept the MP inference and reject the $\mathrm{AC}$ inference for the same major premise (in line with previous studies, e.g., Markovits \& Lortie-Forgues, 2011).

\section{Study 1}

Previous studies have shown that children of 6 to 7 years of age are capable of simple logical reasoning when familiar category-based premises are used (e.g., "If an animal is a dog, then it has four legs"); although at a fairly low level (Markovits, 2000; Markovits \& Thompson, 2008). This suggests that the beginnings of the ability to reason logically could be found at an earlier preschool level using familiar content. Most studies conducted with preschool children have assessed deductive reasoning through responding to logically certain inferences equivalent to the MP inference (Dias \& Harris, 1988, 1990; Hawkins et al., 1984; Richards \& Sanderson, 1999). Understanding the MP inference requires the ability to accept the major premise as true, which is an important component of logical reasoning. However, basic deductive reasoning also requires the ability to distinguish between valid and invalid conclusions. The simplest measure of this latter is given by the ability to reject the AC inferences. Thus, as has been previously argued (e.g., Markovits \& Lortie-Forgues, 2011), the most straightforward measure of simple deductive reasoning involves both the ability to accept the MP inference and to reject the AC inference.

The purpose of this first study was thus to determine whether preschool children are able to reason logically (i.e., to simultaneously accept the MP inference and reject the AC inference) using familiar category-based premises and to evaluate the extent to which inhibitory and generation capacities are related to this ability. To examine these questions, we initially decided to examine correlations between tasks that involve idea generation, inhibition, and simple logical reasoning.
To measure idea generation, we created a task in which children could generate alternative ideas from an initial set of information. This task is similar to some divergent thinking measures (Guilford, 1967; Runco, 1992; Torrance, 1974; Wallach \& Kogan, 1965). Divergent thinking measures have been used in developmental studies, but those were not explicitly designed for preschool children (Bijvoet-van den Berg \& Hoicka, 2014). It should be noted that Defeyter, Avons, and German (2007) have used classic divergent thinking measures with 5-year-olds. However, their specific questions (e.g., different uses for a brick, a barrel) did not seem to be adequately familiar to preschool children. We thus decided to construct a generation task with questions designed to be accessible to very young children (e.g., how to make noise). Children were also given two explicit examples of alternative ideas (e.g., use a whistle and tear a sheet of paper).

We also included a measure of inhibitory control. This refers to an executive function that allows suppression of salient thoughts or actions that are irrelevant for the task at hand. It should be noted that there are other conceptions of inhibition (Miyake et al., 2000), and a variety of measures associated with each. In fact, Nigg (2000) has proposed a taxonomy to classify deliberate inhibition processes into four types (see also Friedman \& Miyake, 2004). These are interference control, cognitive inhibition, behavioral inhibition, and oculomotor inhibition. Many different tasks have been used to assess inhibitory control in young children. For instance, the Stroop Day-Night test aims to examine inhibition of prepotent verbal associations (e.g., Gerstadt et al., 1994). Other assessment tools, such as the Simon Says game (LaVoie, Anderson, Fraze, \& Johnson, 1981; Strommen, 1973), rather examine the ability to respond to specific commands while inhibiting others. For the purpose of the following studies, the measure of inhibitory capacity was chosen to estimate the extent to which children can monitor the conflict between competing rule representations and inhibit the most salient (and inappropriate) representation.

We decided to use the Dimensional Change Card Sort task (DCCS; Zelazo, 2006), which has been used in the age range we examine here. This measure is considered to be a reliable estimate of executive functioning and cognitive control in preschool children (Carlson, 2005; Zelazo, 2006, Zelazo et al., 2003). There is nonetheless some dispute about how to interpret this task. According to cognitive complexity and control theory (Frye, Zelazo, \& Burack, 1998; Zelazo \& Frye, 1998; Zelazo et al., 2003), success on the task occurs when children can use a higher-order rule for selecting the appropriate sorting rule (Happaney \& Zelazo, 2003). This representational flexibility in turn enables conflict monitoring and inhibition of inappropriate responses (Espinet, Anderson, \& Zelazo, 2012). The DCCS was designed as a broad measure of executive function (Zelazo, 2006). However, Diamond and collaborators (see also Kloo \& Perner, 2005) have provided 
evidence that performance on the DCCS is highly related to pure inhibitory capacity because it specifically requires inhibition of the previously relevant sorting rule (Diamond, Carlson, \& Beck, 2005; Diamond \& Kirkham, 2005; Kirkham, Cruess, \& Diamond, 2003; Rennie, Bull, \& Diamond, 2004). This dimension corresponds quite closely to the idea that young children's difficulty with reasoning is closely related to difficulty in inhibiting a suggested inference rule (MP) or other irrelevant information.

\section{Method}

Participants A total of 32 preschool children (Average age $=$ 53.5 months; 21 boys, 11 girls; age range 41-64 months) participated in the study. They were recruited in a day care center in the region of Montreal, Quebec. All participants were native French speakers. Every parent signed a consent form that allowed their child to participate in the study.

\section{Material}

Generation task Three different problems were administered in a fixed order to all participants. The experimenters were allowed to ask children if they had more ideas to give and to repeat the question if necessary. However, they were neither allowed to give positive/ negative feedback nor encouragement. There was no time limit imposed, and the experimenters moved on to the next question when the child told that he or she had no more ideas to give. The problems, translated from French (see the Appendix for the French verbatim of the tasks used in both studies), were presented verbally as follows:

1. "We can make noise with many things. For example, we can use a whistle. We can also make noise with more original things. For example, by tearing a sheet of paper. Can you tell me other ways of making noise? Give me as many ideas as you can."

2. "We can give many things as a gift. For example, we can give a soft toy. We can also give something more original. For example, we can give chocolate. Can you tell me other things to be given as a gift? Give me as many ideas as you can."

3. "We can get dirty with many things. For example, we can get dirty with mud. We can also get dirty with something more original. For example, with ketchup. Can you tell me other ways of getting dirty? Give me as many ideas as you can."

Inhibition task The DCCS task was given using the standardized procedure (Zelazo, 2006). Precisely, children are asked to sort a set of cards (e.g., red rabbits and blue boats) into boxes with target cards (e.g., blue rabbit and red boat), following an explicit rule of the form "If $\mathrm{P}$ then $\mathrm{Q}$, and if A then B." There are three distinct phases. The two initial phases correspond to the standard version of the task, whereas the final phase is used as an advanced version for older children. In the first phase, the sorting dimension is the color of the card, thereby presented with the rule "If the card is red, then you put it here, but if the card is blue, then you put it there." In the second phase, children are required to switch and use the alternative dimension (i.e., shape), which is stated by the rule "If the card is a rabbit, then you put it here, but if the card is a boat, then you put it there." Children are asked to sort six cards on each of these phases. The third phase requires children to shift dimensional focus repeatedly across the sorts. The cards are presented either with or without a black border. The sorting rule is expressed as "If the card has a black border, then you have to play the color game, but if the card does not have a black border, then you have to play the shape game." Children are asked to sort 12 cards on the third phase. Note that children neither have to guess nor retain the rules throughout the phases, because they are given verbally by the experimenter before each sort. Moreover, there is a rule check before starting to sort the cards on each phases. This consists of asking the child to point where the cards have to be placed according to the rule given previously.

The developmental pattern observed with this task is well documented (Kirkham et al., 2003; Zelazo et al., 2003). While 3 -year-old children succeed at maintaining the first rule and sorting the first set according to it, they generally fail at switching dimensions in the second phase (i.e., shape) by perseverating with the initial criterion (i.e., color). In contrast, 4- and 5-year-old children successfully sort the cards in the second phase. However, their success in the third phase is not guaranteed. It should also be noted that there is no difference between performances whether the initial dimension is color or shape.

Logical reasoning task. Logical reasoning was measured with three sets of problems, each of which presented a major and minor premises corresponding to the MP and the AC inferences; although to facilitate understanding, we used the syllogistic form "All P are Q." The content was adapted for young children (Markovits, 2000; Markovits et al., 1996). We asked children what they thought about the major premise statement to make sure they understood the rule. For each problem set, children were first asked to evaluate an $\mathrm{AC}$ inference followed by an MP inference. It should be noted that there is no evidence of the existence of order effects between the $\mathrm{MP}$ and $\mathrm{AC}$ inferences. Finally, children were also asked 
to justify their responses. The problems were administered in the same order to all participants. The problems, translated from French, were as follows:

1. Someone told me that all dogs have legs.

AC A friend of mine has an animal with legs.

Is it certain that his animal is a dog? Why?

MP Another friend has a dog.

Is it certain that his dog has legs? Why?

2. Someone told me that all cactus have thorns.

AC A friend of mine bought a plant with thorns.

Is it certain that his plant is a cactus? Why?

MP Another friend bought $a$ cactus.

Is it certain that his plant has thorns? Why?

3. Someone told me that all cars have wheels.

AC A friend of mine saw a vehicle with wheels.

Is it certain that the vehicle is a car? Why?

MP Another friend saw a car.

Is it certain that the car has wheels? Why?

Very similar problems have been used with 6-year-olds (Markovits, 2000), and the behavior of the children in this study certainly suggested that they understood the terms used. To confirm this, we surveyed 11 experienced educators about children's ability to understand these terms. None of the terms were considered to be difficult, with the possible exception of the "All cactus have thorns" problem. This was not used in Study 2.

Procedure Children were examined individually in a quiet room by a trained experimenter. The experimentation was presented as a playtime and took around $15 \mathrm{mi}-$ nutes to complete. Children were first administered either the generation task followed by the inhibition task and the reasoning task (first order), or the inhibition task, followed by the generation task and the reasoning task (second order). Answers were recorded by the experimenter.

\section{Results and discussion}

We first calculated a score for each of the three tasks. Responses to the generation task were rated by evaluating the number of categories covered by the responses over each of the three problems. We refer to this as the flexibility score. This was considered to be a better measure than the total number of ideas produced (i.e., fluency) because one can generate many elements within a unique category by simple associative processes. Category judgements were done individually by two coders. The coders were instructed to assign a letter to each different idea. When an idea was part of a different semantic category, a new letter was assigned. If an idea from an already stated category occurred further in the chain of ideas, then the letter assigned was the one already used for the other idea (see the Appendix for an example of category judgments). It should be noted that we did not create an a priori list of categories because judgments were not ambiguous. Children usually followed very simple categories. For instance, most of the ideas given for the "how to make noise" problem were musical instruments (e.g., piano, guitar), body actions (e.g., to shout, to blow) or object actions (e.g., throw a ball on the wall, dropping something on the floor). Weighted Cohen's kappa shows good interrater agreement $\left(k_{w}=0.798\right)$. The flexibility score is thus the average number of distinct categories used across the three problems. For completeness, we also decided to analyze the fluency score. This is the average number of answers provided across the three problems.

The inhibition score was calculated according to the standard scoring method of the DCCS task (Zelazo, 2006). Points were given if the child reached the threshold of correct sorts on each phase. Precisely, one point was given when the child correctly sorted at least 5 cards out of 6 on the first phase, but no point was given otherwise. For the second phase, one point was also given when at least 5 cards out of 6 were correctly sorted. For the third phase, one point was finally given when at least 9 cards out of 12 were correctly sorted. Inhibition scores were thus situated within a range of zero to three points, but the scores were actually dichotomous ( 1 or 2 ) because every children succeeded at the first phase, but none correctly sorted nine cards on the third phase.

On the logical reasoning task, children were given one point if they responded logically to both type of inferences on each of the problem. That is, if they accepted the conclusion of the MP inference and rejected the conclusion of the $\mathrm{AC}$ inference as well. A logical reasoning score was calculated by summing the number of points accorded (varying from zero to three).

Table 1 shows an overview of the mean scores on each task as a function of order. To establish whether the order of presentation had an effect on the scores, we performed $t$ tests with generation, inhibition, and logical reasoning scores as dependent variables, and order (first order; second order) as 
Table 1 Mean scores on the generation task (fluency, flexibility), the inhibition task, and the logical reasoning task as a function of order (Order 1, Order 2, Combined)

\begin{tabular}{lllll}
\hline & Generation (Fluency) & Generation (Flexibility) & Inhibition & Logical reasoning \\
\hline Order 1 & $4.62(3.85)$ & $2.02(0.95)$ & $1.53(0.52)$ & $0.60(0.83)$ \\
Order 2 & $5.67(3.19)$ & $2.43(1.12)$ & $1.53(0.51)$ & $1.00(0.94)$ \\
Combined & $5.17(3.50)$ & $2.24(1.05)$ & $1.53(0.51)$ & $.81(.90)$ \\
\hline
\end{tabular}

Note. Numbers in parentheses are standard deviations

independent variables. This showed that order had no significant effect on the scores. As can be seen from Table 1, the overall rate of logical reasoning, which requires simultaneous acceptance of the MP and rejection of the AC inferences, was $27 \%$. For completeness, we analyzed the MP and the AC inferences separately. As expected, mean number of correct responses was much higher for the MP inference $(M=2.91$, $S D=0.39)$ than for the AC inference $(M=0.91, S D=0.89)$. Although the rate of logical reasoning was relatively low, it compares favorably with that observed in somewhat older children.

We also examined children's explicit justifications. Justifications were sorted into four categories. The first included justifications referring to the terms of the major premise presented (e.g., for the major premise "All dogs have legs," "Because it has legs," and "Because it's a dog" are examples of this form of justification). The second included justifications referring either to a specific alternative antecedent (e.g., "Because cats have legs too") or to a general alternative (e.g., "Because other animals have legs too"). The third category included justifications referring to anecdotal stories (e.g., "Because I have a dog at home"). The fourth category was comprised of "I don't know" responses. Justifications that matched none of the categories above were reported as being unclassifiable. Overall, $44.8 \%$ of the justifications referred to premise terms and $9.9 \%$ referred to potential alternative antecedents, whereas $30.7 \%$ were "I don't know" responses, $6.3 \%$ were anecdotal and $8.3 \%$ were unclassifiable. This suggests that a majority of children processed the problems and were reasoning explicitly. Further analysis showed that $57.3 \%$ of the justifications to the MP inferences referred to premise terms; while none referred to potential alternative antecedents ("I don't know": $28.1 \%$, anecdotal: $6.2 \%$, unclassifiable: $8.3 \%$ ). For the AC inferences, $32.3 \%$ referred to premise terms and $19.8 \%$ to potential alternative antecedents ("I don't know": $33.3 \%$, anecdotal: $6.2 \%$, unclassifiable: $8.3 \%$ ). It is clear that the frequency of use of each type of justification differs between MP and AC inferences. To confirm this, a chi-square analysis was performed to examine the relation between the type of inference and the justifications. This analysis was done using three categories of justification. The two first categories were justifications referring to premise terms and justifications referring to alternative antecedents. The third category was comprised of the three other types of justification. This showed a significant difference, $\chi^{2}(2, N=192)=25.99, p<.001$. This suggests that children processed the MP and AC inferences in a different way. A more detailed analysis revealed that children are more likely to give justifications referring to premise terms with the MP inference than they are with the AC inference. However, they tend to give more justifications referring to alternative antecedents with the $\mathrm{AC}$ inference.

We also analyzed justifications according to the response given to $\mathrm{AC}$ inferences. When the conclusion to the $\mathrm{AC}$ inference was correctly rejected, $65.5 \%$ of justifications referred to at least one alternative antecedent and $3.4 \%$ referred to premise's terms ("I don't know": $24.1 \%$, anecdotal: $3.4 \%$, unclassifiable: $3.4 \%$ ). However, when the conclusion to the AC inference was not correctly rejected, we observe that none of the justifications referred to an alternative antecedent whereas $44.8 \%$ referred to premise's terms (“I don't know": $37.3 \%$, anecdotal: $7.5 \%$, unclassifiable: $10.4 \%$ ). This comparison thus suggests that the justifications were mostly appropriate when the AC inferences were correctly rejected. In other words, children mostly generated information that was consistent with the rejection of the $\mathrm{AC}$ inference.

We then examined correlations between age (in months), logical reasoning scores, and both inhibition and generation scores (see Table 2). It is worth mentioning that a single order of administration of the tasks would have been more appropriate for correlational analysis. However, the pattern of correlations does not differ according to order. Table 2 shows that age is strongly related to inhibition scores, which is consistent with previous findings using the DCCS task (Zelazo, 2006). However, inhibition scores were unrelated either to logical reasoning scores or to generation scores. In contrast, both the flexibility and the fluency scores of the generation task were positively related to logical reasoning performance. We also performed a partial correlation to examine the relationship between flexibility and logical reasoning scores when controlling for fluency. This showed a significant correlation, $r(29)=.353, p=.05$. However, when flexibility was partialled out, the correlation between fluency and logical reasoning scores was not significant, $r(29)=.09, p=n s$.

To examine to what extent flexibility scores are unique predictors of logical reasoning performance, we performed a 
Table 2 Correlations between age (in months) and generation (fluency, flexibility), inhibition, and logical reasoning scores

\begin{tabular}{lllll}
\hline & Generation (Fluency) & Generation (Flexibility) & Inhibition & Logical reasoning \\
\hline Age & .15 & .05 & $.50^{* *}$ & .07 \\
Generation (Fluency) & & $.63^{* *}$ & -.28 & $.37^{*}$ \\
Generation (Flexibility) & & & -.15 & $.48^{* *}$ \\
Inhibition & & & -.06 \\
\hline
\end{tabular}

$* p<.05 . * * p<.001$

hierarchical regression, with logical reasoning score as the dependent variable and with age (in months), inhibition, and flexibility scores as independent variables. We decided to enter age in the model because it might be related to other cognitive factors that could influence logical reasoning scores other than inhibitory capacity. Inhibition score and age were entered into the model first, followed by the flexibility score. This showed that $1.7 \%$ of the variance in the logical reasoning score is explained by both inhibition and age. The flexibility score explained a significant proportion of the variance $(23.7 \%)$ in logical reasoning, above that explained by age and inhibition, $F(3,28)=2.91, p=.05$.

The results of Study 1 reveal a clear pattern of relations. That is, simple logical reasoning (i.e., the ability to simultaneously accept the MP inference and reject the AC inference) in preschool children is not related to inhibitory capacity (as measured with the DCCS task). By contrast, performance on the generation task, as measured with both the fluency and flexibility scores, is clearly related to simple logical reasoning performance. However, flexibility is more strongly related to logical reasoning than is fluency. More specifically, the relation between flexibility and logical reasoning scores was maintained even when controlling for fluency. These results reinforce the idea that idea generation is a key component in the logical reasoning process of preschool children. It is also important to note that a moderate proportion of preschool children were able to reason logically with familiar categorybased premises.

\section{Study 2}

The results obtained in Study 1 show that preschool children are indeed capable of some degree of basic logical reasoning; that is, they are able to both accept the MP inference and to reject the AC inference for the same premise. The results also suggest that early logical reasoning is more closely related to the ability to generate alternative ideas than to inhibitory capacity as measured with the DCCS task. It should be noted that given the high rates of MP acceptance that children showed, these relations are concentrated on the latter component of logical reasoning (i.e., rejection of the $\mathrm{AC}$ inference). Thus, these results indicate that the ability to reason logically in preschool children is related to individual differences in idea generation more than to individual differences in inhibitory control. However, previous studies have indicated that it might be possible to manipulate dimensions involved in individual differences in order to directly influence reasoning. More specifically, these studies have shown that preceding reasoning tasks by a measure of alternatives generation can improve reasoning, but only when the form of alternatives generation is appropriate for the level of reasoning examined (Markovits, 2014b; Markovits \& Brunet, 2012; Markovits \& Lortie-Forgues, 2011). This has been interpreted as being due to a priming effect, where the measure used can activate the underlying processes, when these are indeed relevant. A similar sort of order-based priming effect for the DCCS and theory of mind tasks requiring inhibition has also been shown (Kloo \& Perner, 2003). We thus decided to replicate the basic design of Study 1, but with two conditions. In the first condition, the reasoning task was preceded by the generation task, while in the second, the reasoning task was preceded by the inhibition task. Our basic hypothesis suggested that reasoning would be superior in the former condition than in the latter.

\section{Method}

Participants A total of 32 preschool children (Average age $=$ 47.06 months; 16 boys, 16 girls; age range 32-61 months) participated in the study. They were recruited in a day care center in the region of Montreal, Quebec. All participants were native French speakers. Every parent signed a consent form that allowed their child to participate in the study.

\section{Material}

Generation task We used the same problems as in Study 1.

Inhibition task The full version of the DCCS task was generally much longer than the generation task, as reported by the experimenters from Study 1. Furthermore, none of the children succeeded the third phase. Given this, we decided to use the standard version of the DCCS task (i.e., Phases 1 and 2 of the task). Note that children still have to sort the same quantity of cards as in Phases 1 and 2 of Study 1.This modification is suitable for this age range and takes less time than the full 
version. Furthermore, this allowed for both the generation and inhibition task to take as much time to administer and for the experimental conditions to be more balanced.

Logical reasoning task The logical reasoning problems were similar to those used in Study 1, except we removed the "All cactus have thorns" problem. We also decided to add two additional problem sets. This choice was made to ensure a more reliable measure of simple logical reasoning and to estimate more precisely the impact of the experimental manipulation. Again, the five problem sets were administered in the same order to all participants and were the following (translated from French):

1. Someone told me that all dogs have legs.

AC A friend of mine has an animal with legs.

Is it certain that his animal is a dog? Why?

MP Another friend has a dog.

Is it certain that his dog has legs? Why?

2. Someone told me that all flies can fly. ${ }^{1}$

AC A friend of mine saw an insect that fly.

Is it certain that this insect is a fly? Why?

MP Another friend saw a fly.

Is it certain that the fly can fly? Why?

3. Someone told me that all trucks have wheels.

AC A friend of mine saw a vehicle with wheels.

Is it certain that the vehicle is a truck? Why?

MP Another friend saw a truck.

Is it certain that the truck has wheels? Why?

4. Someone told me that all balloons are round.

AC A friend of mine saw a round object.

Is it certain that the object is a balloon? Why?

\footnotetext{
${ }^{1}$ It should be noted that the French noun for the insect fly is different from the French verb fly. See the Appendix for additional details.
}

MP Another friend saw a balloon.

Is it certain that the balloon is round? Why?

5. Someone told me that all boots are worn on feet.

AC A friend of mine saw something that is worn on feet.

Is it certain that this thing is worn on feet? Why?

MP Another friend saw boots.

Is it certain that the boots are worn on feet? Why?

Procedure Children were examined individually in a quiet room by a trained experimenter. Each session took around 10 minutes to complete. We used a between-subjects design involving two conditions. Children were randomly administered either the generation task followed by the logical reasoning task (generation prime condition), or the inhibition task followed by the logical reasoning task (inhibition prime condition). Responses were recorded by the experimenter.

\section{Results and discussion}

As before, we calculated numbers of correct responses on the MP and AC inferences and a logical reasoning score, which was the number of problems for which responses on both inferences were correct (now ranging from zero to five). Table 3 shows the mean number of logically correct responses for the MP inferences, the AC inferences and the total logical reasoning score as a function of condition (generation prime, inhibition prime). Similarly to Study 1, MP inferences showed extremely high levels of correct responses $(98.1 \%$ ), while global mean rates of logical responses to the AC inferences was much lower $(18.8 \%)$.

We then performed an ANOVA with logical reasoning score as the dependent variable, condition (generation prime; inhibition prime) as independent variable and age (in months) as covariate. This showed a significant effect of condition, $F(1,29)=4.39, p<.05$, partial eta $^{2}=.132$. Age was not

Table 3 Mean number of logically correct responses for the MP inferences, the AC inferences, and mean logical reasoning score as a function of condition (generation prime, inhibition prime)

\begin{tabular}{llll}
\hline & \multicolumn{2}{l}{ Inference types } & Logical reasoning \\
\hline Condition & MP & AC & Score \\
Generation prime & $5.00(.00)$ & $1.50(1.93)$ & $1.50(1.93)$ \\
Inhibition prime & $4.81(.54)$ & $.38(.81)$ & $.38(.81)$ \\
\hline
\end{tabular}

Note. Numbers in parentheses are standard deviations 
related to the logical reasoning score, $F(1,29)=.01, p=n s$. Children who performed the generation task beforehand had significantly greater logical reasoning scores $(M=1.50 ; S D=$ 1.93) than those who did the inhibition task beforehand $(M=$ $.38 ; S D=.80$ ).

We also examined children's explicit justifications on the reasoning problems. Justifications were sorted into the same four categories as in Study 1. Overall, $68.1 \%$ of the justifications referred to premise terms and $9.0 \%$ referred to potential alternative antecedents, whereas $21.9 \%$ were "I don't know" responses, $3.9 \%$ were anecdotal, and $7.9 \%$ were unclassifiable. Further analysis showed that $67.7 \%$ of the justifications to the MP inferences referred to premise terms while $1.9 \%$ referred to potential alternative antecedents ("I don't know": $20.0 \%$, anecdotal: $2.6 \%$, unclassifiable: $7.7 \%$ ). For the AC inferences, $55.8 \%$ referred to premise terms and $14.1 \%$ to alternative antecedents (“I don't know": $19.2 \%$, anecdotal: $4.5 \%$, unclassifiable: $6.4 \%$ ). We performed a chi-square analysis to examine the relation between inference and justification types (premise terms; alternative antecedents; others). This showed a significant difference, $\chi^{2}(2, N=311)=16.12$, $p<.001$. A more detailed analysis mirrors the results of Study 1. Children are more likely to give justifications referring to premise terms with the MP inference than they are with the $\mathrm{AC}$ inference. However, they tend to give more justifications referring to alternative antecedents with the $\mathrm{AC}$ inference.

We also analyzed justifications according to the response given to $\mathrm{AC}$ inferences. When the conclusion to the $\mathrm{AC}$ inference was correctly rejected, $63.3 \%$ of justifications referred to at least one alternative antecedent and $10.0 \%$ referred to premise's terms ("I don't know": $23.3 \%$, anecdotal: $3.3 \%$, unclassifiable: $0 \%$ ). However, when the conclusion to the AC inference was mistakenly accepted, we observe that $2.4 \%$ of the justifications referred to an alternative antecedent whereas $66.7 \%$ referred to premise's terms ("I don't know": $18.3 \%$, anecdotal: $4.8 \%$, unclassifiable: $7.9 \%$ ). This comparison thus suggests that the justifications were mostly appropriate when the AC inferences were correctly rejected.

Finally, we analyzed justifications according to the experimental condition. For the generation prime condition, $57.6 \%$ of the justifications referred to premise terms and $13.2 \%$ to alternative antecedents ("I don't know": $18.5 \%$, anecdotal: $2.6 \%$, unclassifiable: $7.9 \%$ ). For the inhibition prime condition, $65.6 \%$ referred to premise terms and $3.1 \%$ to alternative antecedents ("I don't know": $20.6 \%$, anecdotal: $4.4 \%$, unclassifiable: $6.2 \%$ ). We then performed a chi-square analysis to examine more precisely the effect of the experimental condition (generation prime; inhibition prime) on the justifications (premise terms; alternative antecedents; others). This showed a significant difference between the conditions, $\chi^{2}(2, N=311)=10.82, p<.01$. We decided to conduct a post hoc analysis using Bonferroni adjusted alpha levels of .005 (.05/9). Results indicated that children are more likely to give justifications referring to alternative antecedents in the generation prime condition than they are in the inhibition prime condition, $\chi^{2}(1, N=25)=9.00, p<.005$.

These results show that preschool children who are given a Generation task beforehand show significantly improved levels of logical reasoning compared to children who are given an inhibition task beforehand. Additionally, children who are given a generation task also tend to produce more frequently justifications referring to alternative antecedents. This tendency provides some insight into the possible effect of the generation task on subsequent reasoning. By itself, the conclusions of Study 2 are far from unambiguous, but the results nonetheless reinforce those of Study 1.

\section{General discussion}

Conditional (if-then) reasoning is a critical component of advanced thinking. Understanding what factors are important in the early development of the ability to reason logically is important, both theoretically and practically. In these studies, we have examined two factors that have been shown to impact logical reasoning in older children: inhibitory capacity and the ability to generate alternative ideas.

The results of these two studies provide evidence that the ability to generate alternative ideas is more important for the very early development of basic logical reasoning, in particular, the ability to correctly reject the AC inference, than is inhibitory capacity. Study 1 shows that logical reasoning in preschool children is more strongly correlated with a measure of idea generation than to a measure of inhibitory capacity (i.e., the DCCS task). Study 2 provides experimental support for this conclusion, showing that preceding reasoning with a generation task significantly improves preschool children's reasoning compared to an inhibitory task.

While these results suggest that idea generation is more important than inhibitory capacity, we cannot conclude that inhibition is not important for reasoning. The choice of the DCCS as a measure of inhibitory capacity is, as has been stated previously, somewhat controversial. If this is more of a broader measure of executive function (Zelazo, 2006), then it is possible that a more focused measure might give stronger correlations than we have observed in these studies. However, even if the DCCS is related to more dimensions of executive function, it should nonetheless measure inhibition (Diamond \& Kirkham, 2005) and the lack of any relationship to early reasoning remains significant.

In fact, there is evidence that inhibition is an important component of reasoning in older children and adults. This relation is most clearly observed in the context of information that puts into doubt the necessity of a conditional rule. For example, studies have found a relationship between elementary school children's inhibitory capacity and logical reasoning with premises that are empirically false (Handley, Capon, Beveridge, Dennis, \& Evans, 2004; Simoneau \& Markovits, 2003). Another similar context concerns the effects of 
disabling conditions. Disabling conditions refer to stored information that could invalidate a given conditional rule (Cummins, 1995; Cummins, Lubart, Alksnis, \& Rist, 1991). Several studies have shown that the number of disablers stored in memory is associated with a decrease in the acceptance rate of the MP (and MT) inference (Byrne, 1989; Cummins, 1995; De Neys, Schaeken, \& D’Ydewalle, 2002, 2003; Thompson, 1994). Accepting the MP inference is associated with the ability to inhibit the activation of disabling conditions (De Neys, Schaeken, \& D'Y dewalle, 2005; De Neys \& Everaerts, 2008). However, while this form of inhibition is clearly an important component of reasoning among older children and adults, there is evidence that suggests that it might have a limited impact in very young children's reasoning (Janveau \& Markovits, 1999). This is consistent with these results, which suggest that early logical reasoning is particularly dependent on the capacity to generate alternatives.

This is, in turn, consistent with the fact that both studies show that young children accept the MP inference at a very high rate and that their difficulties in logical reasoning are concentrated on the ability to reject the AC inference. However, despite this difficulty, these results do show that very young children can reason correctly with both the MP and the AC inferences, at least under certain conditions. To our knowledge, although there is evidence that older elementary school children are able to reason logically with premises similar to those employed here (Markovits, 2000; Markovits \& Thompson, 2008), no studies have examined preschool children's ability to reason with both the MP and the AC inferences. Studies that have looked at younger children have only examined certain inferences equivalent to the MP inference (Dias \& Harris, 1988, 1990; Hawkins et al., 1984; Richards \& Sanderson, 1999). Thus, the results of these studies show that preschool children have the capacity to reason logically in the basic sense we use here, although we cannot exclude the possibility that this capacity must be activated by an alternative ideas generation procedure.

It should be noted that although the basic conclusion is warranted, the absolute level of logical responding among preschool children can be masked by other factors. For example, studies have shown that preschool children are subject to a strong "yes" bias when asked to answer yes-no questions (Heather Fritzley \& Lee, 2003; Okanda \& Itakura, 2010). Such a bias might result in either an overestimation of the ability to accept the MP inference or an underestimation of the ability to reject the AC inference. Thus, absolute levels of logical responding should be treated with caution.

These results are consistent with a general framework that suggests that the ability to generate alternative possibilities is a critical component of reasoning. According to a mental model approach, basic mental models reflect the semantics of premises. The extent to which reasoners construct alternate semantic models that are also consistent with the truth of premises taken in a larger sense is an important extension (Byrne, 2005). For instance, Byrne's (2005) mental model analysis of counterfactual conditionals (e.g., "If I hadn't been wearing a seatbelt, I would have been killed") stresses that such premises trigger the imagination of two simultaneous alternative possibilities. However, these results suggest a broader interpretation of the process of alternative generation.

The idea generation task used here measures not only the ability to generate an alternative semantic interpretation but also the ability to imagine multiple alternatives. This, in turn, strongly mirrors the basic processes observed in the study of divergent thinking, which is conceived as an important process underlying creativity (Acar \& Runco, 2014; Beaty \& Sylvia, 2012; Benedek, Könen, \& Neubauer, 2012; Gilhooly, Fioratou, Anthony, \& Wynn, 2007). Divergent thinking is defined as the ability to generate several ideas or solutions to a problem, whereas convergent thinking consists of generating one correct or conventional answer to a question (Runco \& Acar, 2012). In fact, Markovits (2014a) has recently proposed a model of the development of logical reasoning that explicitly considers some form of divergent thinking as an important developmental component. It should be noted that the generation task used in Studies 1 and 2 is very similar to some common measures of divergent thinking (for a brief review on divergent thinking assessments, see Kaufman, Plucker, \& Baer, 2008). For instance, Torrance Tests of Creative Thinking (TTCT; Torrance, 1974) include tasks in which participants are asked to list as many possible causes for a given action. In a similar vein, the Instances task introduced by Wallach and Kogan (1965) also asks children to name all the things they can think of that make noise.

Divergent thinking has been commonly measured using fluency, flexibility, and originality scores, although the specific scoring methods often differ. These scores are frequently intercorrelated, but they are not redundant and describe different facets of divergent thinking (see Runco \& Acar, 2012; Nusbaum \& Silvia, 2011). However, previous studies show a strong tendency to employ either fluency or originality scores when relating divergent thinking to other cognitive processes or behaviors. Flexibility scores are less frequently used. It is thus interesting to note that the extent to which children can generate ideas across category boundaries (i.e., flexibility score) can be seen as a better indicator of logical ability than the number of alternative ideas provided (i.e., the fluency score). This is also in line with a study by Markovits and Quinn (2002) that has looked at the relationship between retrieval flexibility and conditional reasoning in adults. They found that individual differences in the speed of retrieval of remote alternatives was correlated with the ability to withhold AC inferences. This sheds light on the relative importance of retrieval flexibility during reasoning. This also suggests the idea that creative thinking and deductive reasoning might 
share core processes, and that some form of divergent thinking underlies the early ability to reason logically. In turn, such an association would indicate a novel direction for promoting deductive reasoning in young children.

\section{Appendix}

Table 4 French verbatim

$\begin{array}{ll}\text { Generation task } & \\ \text { Noise } & \text { On peut faire du bruit avec beaucoup de choses, } \\ & \text { comme par exemple avec un sifflet. } \\ & \text { Mais on peut aussi faire du bruit avec des choses } \\ & \text { plus originales, comme par exemple en déchirant } \\ & \text { une feuille de papier. Peux-tu me dire d'autres } \\ & \text { manières de faire du bruit? } \\ \text { Gift } & \text { Il y a beaucoup de choses qu'on peut donner en } \\ & \text { cadeau, comme par exemple un toutou. Mais on } \\ & \text { peut aussi donner quelque de plus original, } \\ & \text { comme par exemple du chocolat. Peux-tu me dire } \\ & \text { d'autres choses qu'on peut donner en cadeau? } \\ \text { On peut se salir avec beaucoup de choses, comme } \\ \text { par exemple avec de la bouette. Mais on peut } \\ \text { aussi se salir avec des choses plus originales, } \\ \text { comme du ketchup. Peux-tu me dire d'autres } \\ \text { manières de se salir? }\end{array}$

Reasoning task

All dogs have legs. Quelqu'un m'a dit que tous les chiens ont des pattes. (AC)Mon ami a un animal qui a des pattes.

Est-ce que c'est certain que son animal est un chien? Pourquoi?

(MP)Mon autre ami a un chien.

Est-ce que c'est certain que son chien a des pattes? Pourquoi?

All cactus have Quelqu'un m'a dit que tous les cactus ont des épines. thorns (AC)Mon ami a acheté une plante avec des épines.

Est-ce que c'est certain que sa plante est un cactus? Pourquoi?

(MP)Mon autre ami a acheté un cactus.

Est-ce que c'est certain que son cactus a des épines? Pourquoi?

All cars have wheels

All flies can fly

Quelqu'un m'a dit que toutes les voitures ont des roues.

(AC)Mon ami a vu un véhicule avec des roues.

Est-ce que c'est certain que son véhicule est une voiture? Pourquoi?

(MP)Mon autre ami a vu une voiture.

Est-ce que c'est certain que la voiture a des roues? Pourquoi?

All balloons are round

Table 4 (continued)

Est-ce que c'est certain que la mouche peut voler? Pourquoi?

All trucks have Quelqu'un m'a dit que tous les camions ont des wheels roues.

(AC)Mon ami a vu un véhicule avec des roues.

Est-ce que c'est certain que son véhicule est un camion? Pourquoi?

(MP)Mon autre ami a vu un camion.

Est-ce que c'est certain que le camion a des roues? Pourquoi?

Quelqu'un m'a dit que tous les ballons sont ronds.

(AC)Mon ami a vu quelque chose de rond.

Est-ce que c'est certain que c'est un ballon? Pourquoi?

(MP)Mon autre ami a vu un ballon.

Est-ce que c'est certain que le ballon est rond? Pourquoi?

All boots are worn Quelqu'un m'a dit que toutes les bottes se portent aux on feet pieds.

(AC)Mon ami porte quelque chose à ses pieds.

Est-ce que c'est certain que c'est des bottes?

Pourquoi?

(MP)Mon autre ami a vu des bottes.

Est-ce que c'est certain qu'elles se portent aux pieds? Pourquoi?

\section{Example of category judgments}

Table 5 "We can get dirty with many things. For example, we can get dirty with mud. We can also get dirty with something more original. For example, with ketchup. Can you tell me other ways of getting dirty? Give me as many ideas as you can."

\begin{tabular}{lll}
\hline Chain of ideas & Category & Category judgments \\
\hline Grass & Outdoor & A \\
Mud & Outdoor & A \\
Cat & Animal & B \\
Mayonnaise & Food & C \\
Mustard & Food & C \\
Ketchup & Food & C \\
Blood & Body & D \\
Chocolate & Food & C \\
Food & Food & C \\
Grass & Outdoor & A \\
Colored pencils & Handwork & E \\
Painting & Handwork & E \\
Mud & Outdoor & A \\
\hline
\end{tabular}




\section{References}

Acar, S., \& Runco, M. A. (2014). Assessing associative distance among ideas elicited by tests of divergent thinking. Creativity Research Journal, 26(2), 229-238. doi:10.1080/10400419.2014.901095

Beaty, R. E., \& Silvia, P. J. (2012). Why do ideas get more creative across time? An executive interpretation of the serial order effect in divergent thinking tasks. Psychology of Aesthetics, Creativity, and the Arts, 6(4), 309-319. doi:10.1037/a0029171

Benedek, M., Könen, T., \& Neubauer, A. C. (2012). Associative abilities underlying creativity. Psychology of Aesthetics, Creativity, and the Arts, 6(3), 273-281. doi:10.1037/a0027059

Bijvoet-van den Berg, S., \& Hoicka, E. (2014). Individual differences and age-related changes in divergent thinking in toddlers and preschoolers. Developmental Psychology, 50(6), 1629-1939. doi:10.1037/a0036131

Braine, M. D. S. (1990). The "natural logic" approach to reasoning. In W. F. Overton (Ed.), Reasoning, necessity, and logic: Developmental perspectives (pp. 135-158). Hillsdale: Erlbaum.

Braine, M. D. S., \& O'Brien, D. P. (1991). A theory of if: A lexical entry, reasoning program, and pragmatic principles. Psychological Review, 98(2), 182-203. doi:10.1037/0033-295X.98.2.182

Byrne, R. M. J. (1989). Suppressing valid inferences with conditionals. Cognition, 31(1), 61-83. doi:10.1016/0010-0277(89)90018-8

Byrne, R. M. J. (2005). The rational imagination: How people create alternatives to reality. Cambridge: MIT Press.

Carlson, S. M. (2005). Developmentally sensitive measures of executive function in preschool children. Developmental Neuropsychology, 28(2), 595-616. doi:10.1207/s15326942dn2802 3

Carlson, S. M., \& Moses, L. J. (2001). Individual differences in inhibitory control and children's theory of mind. Child Development, 72(4), 1032-1053. doi:10.1111/1467-8624.00333

Cummins, D. D. (1995). Naive theories and causal deduction. Memory \& Cognition, 23(5), 646-658. doi:10.3758/BF03197265

Cummins, D. D., Lubart, T., Alksnis, O., \& Rist, R. (1991). Conditional reasoning and causation. Memory \& Cognition, 19(3), 274-282. doi:10.3758/BF03211151

De Neys, W., \& Everaerts, D. (2008). Developmental trends in everyday conditional reasoning: The retrieval and inhibition interplay. Journal of Experimental Child Psychology, 100(4), 252-263. doi:10.1016/j. jecp.2008.03.003

De Neys, W., Schaeken, W., \& D'ydewalle, G. (2002). Causal conditional reasoning and semantic memory retrieval: A test of the semantic memory framework. Memory \& Cognition, 30(6), 908-920. doi:10.3758/BF03195776

De Neys, W., Schaeken, W., \& D’Ydewalle, G. (2003). Inference suppression and semantic memory retrieval: Every counterexample counts. Memory \& Cognition, 31(4), 581-595. doi:10.3758 /BF03196099

De Neys, W., Schaeken, W., \& D'Ydewalle, G. (2005). Working memory and everyday conditional reasoning: Retrieval and inhibition of stored counterexamples. Thinking \& Reasoning, 11(4), 349-381.

Defeyter, M. A., Avons, S. E., \& German, T. C. (2007). Developmental changes in information central to artifact representation: Evidence from ‘functional fluency' tasks. Developmental Science, 10(5), 538546. doi:10.1111/j.1467-7687.2007.00617.x

Diamond, A., Carlson, S. M., \& Beck, D. M. (2005). Preschool children's performance in task switching on the dimensional change card sort task: Separating the dimensions aids the ability to switch. Developmental Neuropsychology, 28(2), 689-729. doi:10.1207 /s15326942dn2802 7

Diamond, A., \& Kirkham, N. (2005). Not quite as grown-up as we like to think parallels between cognition in childhood and adulthood. Psychological Science, 16(4), 291-297. doi:10.1111/j.09567976.2005.01530.x
Diamond, A., Kirkham, N., \& Amso, D. (2002). Conditions under which young children can hold two rules in mind and inhibit a prepotent response. Developmental Psychology, 38(3), 352-362. doi:10.1037 /0012-1649.38.3.352

Diamond, A., \& Taylor, C. (1996). Development of an aspect of executive control: Development of the abilities to remember what I said and to "Do as I say, not as I do". Developmental Psychobiology, 29(4), 315-334.

Dias, M. G., \& Harris, P. L. (1988). The effect of make-believe play on deductive reasoning. British Journal of Developmental Psychology, 6(3), 207-221. doi:10.1111/j.2044-835X.1988.tb01095.x

Dias, M. G., \& Harris, P. L. (1990). The influence of the imagination on reasoning by young children. British Journal of Developmental Psychology, 8(4), 305-318. doi:10.1111/j.2044-835X.1990. tb00847.x

Dias, M. G., Roazzi, A., O’Brien, D. P., \& Harris, P. L. (2005). Logical reasoning and fantasy contexts: Eliminating differences between children with and without experience in school. Interamerican Journal of Psychology, 39(1), 13-22.

Espinet, S. D., Anderson, J. E., \& Zelazo, P. D. (2012). N2 amplitude as a neural marker of executive function in young children: An ERP study of children who switch versus perseverate on the dimensional change card sort. Developmental Cognitive Neuroscience, 2(1), S49-S58. doi:10.1016/j.den.2011.12.002

Evans, J. S. B., Newstead, S. E., \& Byrne, R. M. (Eds.). (1993). Human reasoning: The psychology of deduction. Hove: Erlbaum.

Friedman, N. P., \& Miyake, A. (2004). The relations among inhibition and interference control functions: A latent-variable analysis. Journal of Experimental Psychology: General, 133(1), 101-135. doi:10.1037/0096-3445.133.1.101

Frye, D., Zelazo, P. D., \& Burack, J. A. (1998). Cognitive complexity and control: I. Theory of mind in typical and atypical development. Current Directions in Psychological Science, 7(4), 116-121.

Gauffroy, C., \& Barrouillet, P. (2011). The primacy of thinking about possibilities in the development of reasoning. Developmental Psychology, 47(4), 1000-1011. doi:10.1037/a0023269

Gerstadt, C. L., Hong, Y. J., \& Diamond, A. (1994). The relationship between cognition and action: Performance of children $312-7$ years old on a Stroop-like day-night test. Cognition, 53(2), 129-153. doi:10.1016/0010-0277(94)90068-X

Gilhooly, K. J., Fioratou, E., Anthony, S. H., \& Wynn, V. (2007). Divergent thinking: Strategies and executive involvement in generating novel uses for familiar objects. British Journal of Psychology, 98(4), 611-625. doi:10.1111/j.2044-8295.2007.tb00467.x

Guilford, J. P. (1967). The nature of human intelligence. New York: McGraw-Hill.

Handley, S. J., Capon, A., Beveridge, M., Dennis, I., \& Evans, J. S. B. (2004). Working memory, inhibitory control and the development of children's reasoning. Thinking \& Reasoning, 10(2), 175-195. doi:10.1080/13546780442000051

Happaney, K., \& Zelazo, P. D. (2003). Inhibition as a problem in the psychology of behavior. Developmental Science, 6(5), 468-470. doi:10.1111/1467-7687.00301

Hawkins, J., Pea, R. D., Glick, J., \& Scribner, S. (1984). "Merds that laugh don't like mushrooms": Evidence for deductive reasoning by preschoolers. Developmental Psychology, 20(4), 584-594. doi:10.1037/0012-1649.20.4.584

Heather Fritzley, V., \& Lee, K. (2003). Do young children always say yes to yes-no questions? A metadevelopmental study of the affirmation bias. Child Development, 74(5), 1297-1313. doi:10.1111/14678624.00608

Janveau-Brennan, G., \& Markovits, H. (1999). The development of reasoning with causal conditionals. Developmental Psychology, 35(4), 904-911. doi:10.1037/0012-1649.35.4.904

Johnson-Laird, P. N. (2006). How we reason. Oxford: Oxford University Press. Johnson-Laird, P., \& Byrne, R. M. J. (1991). Deduction. Hillsdale: Erlbaum. 
Johnson-Laird, P., \& Byrne, R. M. J. (2002). Conditionals: A theory of meaning, pragmatics and inference. Psychological Review, 109(4), 646-678. doi:10.1037/0033-295X.109.4.646

Kaufman, J. C., Plucker, J. A., \& Baer, J. (2008). Essentials of creativity assessment. Hoboken: Wiley.

Kirkham, N. Z., Cruess, L., \& Diamond, A. (2003). Helping children apply their knowledge to their behavior on a dimension-switching task. Developmental Science, 6(5), 449-467. doi:10.1111/14677687.00300

Kloo, D., \& Perner, J. (2003). Training transfer between card sorting and false belief understanding: Helping children apply conflicting descriptions. Child Development, 74(6), 1823-1839. doi:10.1046 j.1467-8624.2003.00640.x

Kloo, D., \& Perner, J. (2005). Disentangling dimensions in the dimensional change card-sorting task. Developmental Science, 8(1), 44 56. doi:10.1111/j.1467-7687.2005.00392.x

LaVoie, J. C., Anderson, K., Fraze, B., \& Johnson, K. (1981). Modeling, tuition, and sanction effects on self-control at different ages. Journal of Experimental Child Psychology, 31(3), 446-455. doi:10.1016 /0022-0965(81)90029-1

Livesey, D. J., \& Morgan, G. A. (1991). The development of response inhibition in 4-and 5-year-old children. Australian Journal of Psychology, 43(3), 133-137. doi:10.1080/00049539108260137

Markovits, H. (1995). Conditional reasoning with false premises: Fantasy and information retrieval. British Journal of Developmental Psychology, 13(1), 1-11. doi:10.1111/j.2044-835X.1995.tb00660.x

Markovits, H. (2000). A mental model analysis of young children's conditional reasoning with meaningful premises. Thinking \& Reasoning, 6(4), 335-347. doi:10.1080/135467800750038166

Markovits, H. (2014a). How to develop a logical reasoner: A hierarchical model of the role of divergent thinking in the development of conditional reasoning. In H. Markovits (Ed.), The developmental psychology of reasoning and decision-making (pp. 148-164). Hove: Psychology Press.

Markovits, H. (2014b). On the road toward formal reasoning: Reasoning with factual causal and contrary-to-fact causal premises during early adolescence. Journal of Experimental Child Psychology, 128, 3751. doi:10.1016/j.jecp.2014.07.001

Markovits, H., \& Barrouillet, P. (2002). The development of conditional reasoning: A mental model account. Developmental Review, 22(1), 5-36. doi:10.1006/drev.2000.0533

Markovits, H., \& Brunet, M. L. (2012). Priming divergent thinking promotes logical reasoning in 6-to 8-year-olds: But more for high than low SES students. Journal of Cognitive Psychology, 24(8), 9911001. doi:10.1080/20445911.2012.729034

Markovits, H., \& Lortie-Forgues, H. (2011). Conditional reasoning with false premises facilitates the transition between familiar and abstract reasoning. Child Development, 82(2), 646-660. doi:10.1111/j.14678624.2010.01526.x

Markovits, H., \& Quinn, S. (2002). Efficiency of retrieval correlates with "logical" reasoning from causal conditional premises. Memory \& Cognition, 30(5), 696-706. doi:10.3758/BF03196426

Markovits, H., \& Thompson, V. (2008). Different developmental patterns of simple deductive and probabilistic inferential reasoning. Memory \& Cognition, 36(6), 1066-1078. doi:10.3758/MC.36.6.1066

Markovits, H., Venet, M., Janveau-Brennan, G., Malfait, N., Pion, N., \& Vadeboncoeur, I. (1996). Reasoning in young children: Fantasy and information retrieval. Child Development, 67(6), 2857-2872. doi:10.1111/j.1467-8624.1996.tb01892.x

Miyake, A., Friedman, N. P., Emerson, M. J., Witzki, A. H., Howerter, A., \& Wager, T. D. (2000). The unity and diversity of executive functions and their contributions to complex "frontal lobe" tasks: A latent variable analysis. Cognitive Psychology, 41(1), 49-100. doi:10.1006/cogp.1999.0734

Nigg, J. T. (2000). On inhibition/disinhibition in developmental psychopathology: Views from cognitive and personality psychology and a working inhibition taxonomy. Psychological Bulletin, 126(2), 220 246. doi:10.1037/0033-2909.126.2.220

Nusbaum, E. C., \& Silvia, P. J. (2011). Are intelligence and creativity really so different?: Fluid intelligence, executive processes, and strategy use in divergent thinking. Intelligence, 39(1), 36-45. doi:10.1016/j.intell.2010.11.002

O'Brien, D. P., \& Overton, W. F. (1982). Conditional reasoning and the competence-performance issue: A developmental analysis of a training task. Journal of Experimental Child Psychology, 34(2), 274290. doi:10.1016/0022-0965(82)90046-7

Okanda, M., \& Itakura, S. (2010). When do children exhibit a "yes" bias? Child Development, 81(2), 568-580. doi:10.1111/j.14678624.2009.01416.x

Piajet, J. (1987a). Possibility and necessity: Vol. 1. The role of possibility in cognitive development (H. Feider, Trans.). Minneapolis: University of Minnesota Press.

Piajet, J. (1987b). Possibility and necessity: Vol. 2. The role of necessity in cognitive development (H. Feider, Trans.). Minneapolis: University of Minnesota Press.

Quinn, S., \& Markovits, H. (1998). Conditional reasoning, causality, and the structure of semantic memory: Strength of association as a predictive factor for content effects. Cognition, 68(3), B93-B101. doi:10.1016/S0010-0277(98)00053-5

Rennie, D. A., Bull, R., \& Diamond, A. (2004). Executive functioning in preschoolers: Reducing the inhibitory demands of the dimensional change card sort task. Developmental Neuropsychology, 26(1), 423443. doi:10.1207/s15326942dn2601 4

Richards, C. A., \& Sanderson, J. A. (1999). The role of imagination in facilitating deductive reasoning in 2-, 3-and 4-year-olds. Cognition, 72(2), B1-B9. doi:10.1016/S0010-0277(99)00037-2

Rips, L. J. (1983). Cognitive processes in propositional reasoning. Psychological Review, 90(1), 38-71. doi:10.1037/0033-295X.90.1.38

Rips, L. J. (1994). The psychology of proof. Cambridge: MIT Press.

Rumain, B., Connell, J., \& Braine, M. D. (1983). Conversational comprehension processes are responsible for reasoning fallacies in children as well as adults: If is not the biconditional. Developmental Psychology, 19(4), 471-481. doi:10.1037/0012-1649.19.4.471

Runco, M. A. (1992). Children's divergent thinking and creative ideation. Developmental Review, 12(3), 233-264. doi:10.1016/0273-2297(92 )90010-Y

Runco, M. A., \& Acar, S. (2012). Divergent thinking as an indicator of creative potential. Creativity Research Journal, 24(1), 66-75. doi:10.1080/10400419.2012.652929

Simoneau, M., \& Markovits, H. (2003). Reasoning with premises that are not empirically true: Evidence for the role of inhibition and retrieval. Developmental Psychology, 39(6), 964-979. doi:10.1037/00121649.39.6.964

Strommen, E. A. (1973). Verbal self-regulation in a children's game: Impulsive errors on "Simon Says". Child Development, 44(4), 849-853. doi:10.2307/1127737

Thompson, V. A. (1994). Interpretational factors in conditional reasoning. Memory \& Cognition, 22(6), 742-758. doi:10.3758/BF03209259

Torrance, E. P. (1974). The Torrance tests of creative thinking-NormsTechnical manual (Researchth ed.). Princeton: Personnel Press.

Wallach, M., \& Kogan, N. (1965). Modes of thinking in young children. New York: Holt, Rinehart \& Winston.

Zelazo, P. D. (2006). The Dimensional Change Card Sort (DCCS): A method of assessing executive function in children. Nature Protocols, 1(1), 297-301. doi:10.1038/nprot.2006.46

Zelazo, P. D., \& Frye, D. (1998). Cognitive complexity and control: II. The development of executive function in childhood. Current Directions in Psychological Science, 7(4), 121-126.

Zelazo, P. D., Müller, U., Frye, D., Marcovitch, S., Argitis, G., Boseovski, J., .. \& Carlson, S. M. (2003). The development of executive function in early childhood. Monographs of the Society for Research in Child Development, 68(3), i-151. 